\title{
MATERIALISMO HISTÓRICO: TEORIA E POLÍTICA.
}

Historical materialism: theory and politics.

\section{Rogerio Lopes Carvalho *}

Resumo: Escrever um texto sobre o materialismo histórico e o marxismo neste início de século XXI, implica defender a atualidade do materialismo histórico. Isso tem de ser feito em função de uma época em que muitos, mais uma vez, apontam a crise e mesmo a morte do marxismo. Tal diagnóstico se intensificou com a queda do muro de Berlim em 1989 e a derrocada do socialismo real. Esse contexto vai resultar em discursos triunfantes sobre a vitória do capitalismo o que levaria a eternização das formas democráticas liberais, significando mesmo o próprio fim da história.

Palavras-chave: Teoria, Materialismo Histórico, Política.

\begin{abstract}
Writing a text about historical materialism and Marxism at the beginning of the 21st century implies defending the actuality of historical materialism. This has to be done in the light of a time when many, once again, point to the crisis and even the death of Marxism. This diagnosis intensified with the fall of the Berlin Wall in 1989 and the collapse of real socialism. This context will result in triumphant speeches about the victory of capitalism which would lead to the eternalization of liberal democratic forms, meaning even the end of history itself.
\end{abstract}

Keywords: Theory, Historical Materialism, Politics.

As armas da crítica não podem, de fato, substituir a crítica das armas; a força material tem de ser deposta por força material, mas a teoria também se converte em força material uma vez que se apossa dos homens. A teoria é capaz de prender os homens desde que demostre sua verdade face ao homem, desde que se torne radical. Ser radical é atacar o problema em suas raízes. Para o homem, porém, a raiz é o próprio homem. ${ }^{1}$

Escrever um texto sobre o materialismo histórico e o marxismo neste início de século XXI, implica defender a atualidade do materialismo histórico. Isso tem de ser feito em função de uma época em que muitos, mais uma vez, apontam a crise e mesmo a morte do marxismo. Tal diagnóstico se intensificou com a queda do muro de Berlim em 1989 e a derrocada do socialismo real. Esse contexto vai resultar em discursos triunfantes sobre a vitória do capitalismo o que levaria a eternização das formas democráticas liberais, significando mesmo o próprio fim da história. (Fukuyama).

\footnotetext{
* Doutor em História Social pela Universidade de São Paulo (2008). Professor Adjunto da UNISO (Universidade de Sorocaba). 1 Marx, apud: WEFFORT, Francisco C. Marx: política e revolução. In: WEFFORT, Francisco C. (Org.) Os clássicos da política 2. $5^{\text {a }}$ ed. São Paulo: Editora Ática, 1995.
} 
Alguns autores como Lipovetsky ${ }^{2}$, procuram analisar o contexto atual de refluxo do marxismo. Um cenário que ele denomina como hiper-moderno. Se esse autor corretamente se contrapõe ao termo pós-moderno, pois, em realidade, o mundo atual não está em nenhum período histórico para além da modernidade, e sim, na sua mais absoluta radicalização e abrangência. E, além disso, em que pese Lipovetsky reconheça aspectos ambivalentes dos tempos atuais; o que acaba preponderando é um discurso esplêndido a respeito desse novo cenário. Com efeito, a hiper-modernidade seria caracterizada pelo efêmero, pela obsolescência acelerada, em consequência da passagem do capitalismo da produção fordista / taylorista para o capitalismo do consumo e da comunicação de massa. Assim, uma coletividade cada vez mais ampla não viveria mais sob a égide de uma sociedade disciplinar mas mergulhada cada vez mais na sociedade da moda. Nesse cenário desponta o consumo de massa hedonista e os sujeitos da hiper-modernidade se tornaram hiper-narcisistas. Nessa sociedade não caberiam mais utopias, que entram em refluxo, em detrimento de uma sociedade que se relaciona com o consumo como um futuro eufórico, levada a efeito pela globalização neo-liberal e politicamente pelas democracias burguesas.

Lipovetsky lembra timidamente a respeito do desemprego estrutural e do emprego precário, do advento do tempo do risco e da incerteza promovido por essa nova ordem, mas a balança pende para um panorama triunfante da sociedade de consumo hedonista.

Terry Eagleton ${ }^{3}$ ao analisar as várias tendências pós-modernas e mesmo uma perspectiva como a de Lipovetsky, coloca com toda a contundência, de que todas elas representam num certo sentido a derrota política das esquerdas, após as vagas revolucionárias de 1968. Na verdade, mais ou menos marcadas por um discurso ideológico, podemos classificar tais orientações como pautadas por um discurso ingênuo e a maioria de seus proponentes como bobos da corte, de uma sociedade cada vez mais mergulhada nas contradições do capitalismo.

Vivemos, portanto, um momento paradoxal, no qual o refluxo das utopias em geral e do marxismo em particular se dá em meio a reprodução cada vez mais intensa das contradições da relação sócio-metabólica capitalista, no âmbito do neo-liberalismo e da globalização.

Adorno e Horkheimer já escreviam na década de 1940, ao analisarem o progresso do pensamento do contexto da modernidade, a respeito do esclarecimento. O objetivo a ser alcançado era livrar os homens do medo e colocá-los na posição de senhores. "Mas a terra

2 LIPOVETSKY, Gilles. Tempo contra tempo ou a sociedade hiper moderna. In: Os tempos hipermodernos. São Paulo: Bartcarolla, 2004.

3 EAGLETON, Terry. As ilusões do pós-modernismo. Rio de Janeiro: Zahar, 1998. 
totalmente esclarecida resplandece sob o signo de uma calamidade triunfal. O programa do esclarecimento era o desencantamento do mundo."

Marx, em texto de juventude, num de seus primeiros apontamentos para uma crítica da economia política coloca:

O trabalhador se torna tanto mais pobre quanto mais riqueza produz, quanto mais sua produção aumenta em poder e extensão. $\mathrm{O}$ trabalhador se torna uma mercadoria tão mais barata quanto mais mercadorias cria. Com a valorização do mundo das coisas, aumenta em proporção direta a desvalorização do mundo dos homens. ${ }^{5}$

As ponderações acima se mostram mais atuais do que nunca, dessa forma, o pensamento de Marx várias vezes dado como superado, a cada crise capitalista volta como um espectro, a assombrar a consciência dos ideólogos do triunfalismo neo-liberal. Portanto, como escreve o historiador Carlos Rojas: “enquanto houver capitalismo haverá um pensamento crítico destinado a explicar a sua natureza destrutiva e despótica."6

Ademais, vale enfim destacar a famosa meditação de Sartre de que uma suposta superação do marxismo nada mais é do que uma volta ao pré-marxismo ou "apenas uma redescoberta de um pensamento já contido na filosofia que se acreditou superar."

Eric Hobsbawm lembra que em seu tempo de estudante a historiografia ainda estava marcada pela influência da chamada Escola metódica ou positivista, baseada em grande medida na obra do historiador Leopold von Ranke. Nesse sentido, o materialismo histórico vai se constituir como uma teoria historiográfica muito mais sofisticada e superior a historiografia dominante até então. Como coloca Hobsbawm, seus pressupostos fundamentais já estavam estabelecidos na década de 1840, em obras como A ideologia alemã, com efeito:

Essa concepção da história, portanto, baseia-se na exposição do processo real de produção - começando da produção material da vida em si mesma - e abrangendo a forma de relações associadas com e criadas por esse modo de produção, isto é, a sociedade civil em suas várias etapas, enquanto base de toda a história; descrevendo-a em sua ação enquanto Estado, e também explicando como todos os diferentes produtos teóricos e formas de consciência, religião e filosofia, moralidade, etc, etc, dela derivam, e acompanhando o processo de sua formação a partir dessa base, dessa forma, a coisa toda pode, é claro, ser descrita em sua totalidade (e consequentemente, também, a ação recíproca desses vários aspectos entre si. $)^{8}$

4 ADORNO, Theodor; HORKHEIMER, Max. Dialética do esclarecimento: fragmentos filosóficos. Rio de Janeiro: Zahar, 1985, p. 19.

5 MARX, Karl. Manuscritos econômicos - filosóficos. São Paulo: Boitempo, 2004, p. 80.

6 AGUIRRE ROJAS, Carlos Antonio. A historiografia no século XX: História e historiadores entre 1848 e...2025?

São Paulo: Edusp, 2017, p. 77.

7 SARTRE, Jean-Paul. Questão de método. $3^{\mathrm{a}}$ ed. São Paulo: Difusão Europeia do Livro, 1972, p. 12.

8 Marx e Engels, apud: HOBSBAWM, Eric. Marx e a história. In: Sobre história. São Paulo: Cia das Letras, 1998, p. $174-175$. 
Por sua vez Florestan Fernandes mostra que, em grande medida, as limitações da historiografia metódica, se devia ao fato de estar ligada à consciência burguesa. Assim, a consciência histórica burguesa contentava-se com uma historiografia superficial, pulverizada e mistificadora, uma vez que, "a burguesia como classe só instrumentalizou revolucionariamente a liberdade da existência das classes e sua própria hegemonia.". ${ }^{9}$ Como escreve o sociólogo brasileiro, o materialismo histórico coloca em outros patamares o estabelecimento da historiografia enquanto ciência:

Ao constituir-se como ciência, a história tinha de sair de sua pele (o envoltório burguês), ao destruir o seu pesado lastro filosófico - especulativo e empiristaabstrato, armar-se com recursos apropriados à pesquisa empírica rigorosa, à reconstrução histórica objetiva e à explicação causal de totalidades históricas. $(\ldots)^{10}$

Porém, todo o esforço de proposição de uma historiografia enquanto ciência se devia a uma mudança de perspectiva do olhar. Marx passava a olhar a sociedade capitalista da perspectiva do proletário. Assim, o materialismo histórico não pode ser pura e exclusivamente uma teoria historiográfica desvinculada da luta política, como querem alguns autores comentadores da teoria da história formulada por Marx e Engels. ${ }^{11}$ Todo o esforço em colocar a historiografia sob novos padrões da exigência científica deve servir de base à prática política proletária. Aqui, portanto, pensamos o materialismo histórico, sim, como um paradigma historiográfico que deve se articular ao marxismo enquanto ação política.

É esse aspecto dá sentido a uma das grandes contribuições historiográficas do materialismo histórico, a saber, a sua historicidade radical. Nesse sentido, Marx, ao contrário dos economistas políticos e historiadores ligados ao pensamento burguês, procura historicizar os diferentes modos de produção; dessa forma revela o caráter histórico e portanto não eterno do modo de produção capitalista.

Além disso, Marx estava absolutamente na vanguarda das discussões historiográficas quando colocava, no século XIX, que o objeto da investigação é inseparável da situação histórica que o produz. Ou seja, o sujeito-investigador também é um sujeito-histórico. O sujeito do conhecimento (historiador) também está inserido nos fluxos da historicidade. ${ }^{12}$

\footnotetext{
9 FERNANDES, Florestan. (org.). K. Marx, F. Engels. História. Col. Grandes Cientistas Sociais, 36. São Paulo: Ática, 1983, p. 34.

10 Idem. op. cit., p. 34.

11 Sobre essa separação, o historiador José Assunção D' Barros coloca que se deve "separar o materialismo histórico - enquanto paradigma historiográfico que se oferece como alternativa para a compreensão da história e para a elaboração do conhecimento historiográfico - do "marxismo" propriamente dito, no sentido de um certo programa de ação política.” BARROS, José D’ Assunção. Teoria da história 3: Os paradigmas revolucionários. Petrópolis, RJ: Vozes, 2011, p. 17.

12 FERNANDES, Florestan. (org.). K. Marx, F. Engels. História. Col. Grandes Cientistas Sociais, 36. São Paulo: Ática, 1983, p. 36.
} 
Koselleck ${ }^{13}$ mostra como no século XIX, a historiografia metódica buscava um índice de cientificidade através da produção de um conhecimento supostamente imparcial e objetivo. Essas proposições lançam mão da metáfora do espelho, assim, "a imagem que o historiador, semelhante ao espelho, deve refletir não deve ser deturpada, empalidecida ou deformada.". ${ }^{14}$ Tal realismo ingênuo é enfatizado por Ranke, quando refere-se à busca incessante pelo historiador de uma verdade nua e crua, despida de quaisquer adornos. $\mathrm{O}$ velho Ranke sintetiza todas essas assertivas quando coloca: "Eu gostaria de poder apagar o meu próprio eu, dando voz apenas às coisas que se manifestam por meio de forças poderosas." 15

Em sua busca arqueológica sobre o nascimento da modernidade historiográfica, Koselleck descobre a produção de Chladenius que de maneira pioneira, ainda no século XVIII, explicita a relação entre a articulação temporal da história e o ponto de vista do produtor desse conhecimento. Assim,

Há uma razão pela qual conhecemos algo dessa maneira e não de outra. Tratase do ponto de vista a partir do qual se contempla a mesma coisa (...) Desse conceito decorre que aqueles que contemplam algo a partir de diferentes pontos de vista devem necessariamente construir representações diferentes desse objeto. ${ }^{16}$

Dessa forma, o ponto de vista pelo qual o historiador investiga o passado se coloca como fundamental na produção do conhecimento histórico e não pode ser abafado. A história já ocorrida permanece sempre a mesma, mas a historiografia a respeito do passado se fragmenta como um caleidoscópio, conforme as diferentes perspectivas. Pois bem, a monumental crítica da economia política empreendida por Marx só pode ocorrer porque ele parte de um ponto diferente em relação a autores como Adam Smith e David Ricardo que sempre olharam a questão da perspectiva da burguesia. A verdade científica que Marx busca é uma verdade revolucionária, a verdade das classes exploradas pelo capitalismo.

Engels ${ }^{17}$ coloca que o materialismo histórico procura submeter a história anterior a um novo exame, que passa pela luta de classes e a descoberta do caráter inerente da exploração capitalista, a partir da produção da mais-valia, ou seja, a apropriação pelo capitalista do trabalho não pago ao trabalhador. Tal descoberta já estava colocada no texto seminal dos manuscritos econômicos e filosóficos de 1844, escritos por Marx. Destarte,

13 KOSELLECK, Reinhardt. Ponto de vista, perspectiva e temporalidade - contribuição à apreensão historiográfica da história. In: Futuro passado - contribuição à semântica dos tempos históricos. Rio de Janeiro: Contraponto : Ed. PUC-RJ, 2006.

14 Idem. Op. cit., p. 164.

15 Idem. op. cit., p. 164.

16 Idem. op. cit., p. 170.

17 Engels, apud: FERNANDES, Florestan. (org.). K. Marx, F. Engels. História. Col. Grandes Cientistas Sociais, 36. São Paulo: Ática, 1983, p. 406-408. 
A apropriação do objeto tanto aparece como estranhamento que, quanto mais objetos o trabalhador produz, tanto menos pode possuir e tanto mais fica sob o domínio do seu produto, do capital.

$\mathrm{Na}$ determinação de que o trabalhador se relaciona com o produto do seu trabalho como (com) um objeto estranho estão todas estas consequências. Com efeito, segundo este pressuposto está claro: quanto mais o trabalhador se desgasta trabalhando, tanto mais poderoso se torna o mundo objetivo, alheio que ele cria diante de si, tanto mais pobre se torna ele mesmo, seu mundo interior, [e] tanto menos [o trabalhador] pertence a si próprio. [...]

A economia nacional [economia política] oculta o estranhamento na essência do trabalho porque não considera a relação imediata entre o trabalhador [o trabalho] e a produção. Sem dúvida. O trabalho produz maravilhas para os ricos, mas produz privação para o trabalhador. Produz palácios, mas cavernas para o trabalhador. Produz beleza, mas deformação para o trabalhador. Substitui o trabalho por máquinas, mas lança uma parte dos trabalhadores de volta a um trabalho bárbaro e faz da outra parte máquinas. Produz espírito, mas produz imbecilidade, cretinismo para o trabalhador. ${ }^{18}$

Há, portanto, no materialismo histórico, uma intensa relação entre economia, classe social e a política. O que nos leva a um dos aspectos fundamentais do materialismo histórico que é a questão da totalidade. Karel Kosik ${ }^{19}$, nos mostra que a posição da totalidade busca compreender a realidade, procurando sob a superfície e a casualidade dos fenômenos "as conexões internas necessárias", indo para além de uma perspectiva exclusivamente empirista que se limita ao nível das manifestações fenomênicas.

Nesse sentido, é que Marx critica os limites das revoluções burguesas. Segundo Marx, no Estado político os homens levam uma dupla existência uma celestial e a outra terrena. ${ }^{20} \mathrm{Ou}$ seja, a emancipação política colocada pelas revoluções burguesas clássicas podem ser consideradas um avança em relação às sociedades estamentais, mas essa emancipação política, coloca a existência da sociedade de classes e liberta efetivamente apenas uma parte da sociedade, a saber, a burguesia.

No âmbito da comunidade política, ou seja, na esfera celestial estão colocados os diretos políticos postos pela sociedade burguesa, contudo, no contexto da sociedade civil, onde o trabalhador atua como particular, tem de "encarar os outros homens como mero instrumento e se torna joguete de poderes estranhos." ${ }^{21}$ Décio $\mathrm{Saes}^{22}$, influenciado pelo pensamento de Nicos Poulantzas, emprega o conceito de "efeito de isolamento" para apreender essa oposição entre comunidade política e sociedade civil. Com efeito, no contexto do Estado burguês ocorre

18 MARX, Karl. Manuscritos econômicos - filosóficos. São Paulo: Boitempo, 2004, p. 82-83.

19 KOSIK, Karel. Dialética do concreto. Rio de Janeiro: Paz e Terra, 1969.

20 Marx, apud: WEFFORT, Francisco C. Marx: política e revolução. In: WEFFORT, Francisco C. (Org.) Os clássicos da política 2. $5^{\text {a }}$ ed. São Paulo: Editora Ática, 1995, p. 253.

21 Marx, apud: WEFFORT, Francisco C. Marx: política e revolução. In: WEFFORT, Francisco C. (Org.) Os clássicos da política 2. $5^{\text {a }}$ ed. São Paulo: Editora Ática, 1995, p. 253.

22 SAES, Décio. O conceito de Estado Burguês. In: Estado e democracia: Ensaios teóricos. Campinas, SP: IFCH, 1994. 
o processo de conversão dos agentes da produção (classes sociais) em sujeitos jurídico-políticos. Assim, enquanto sujeito do direito individualizado, o trabalhador pode formalmente fluir os direitos políticos concedidos pelo Estado burguês. Dessa forma, a esfera da circulação se constitui como verdadeiro éden dos direitos naturais dos homens, pois, aparentemente, enquanto sujeitos jurídicos individualizados, através de um contrato, estabelecem a troca de equivalentes. No entanto, trata-se de um troca desigual, mas isso não aparece na esfera da circulação enquanto sujeitos individualizados, mas sim, na esfera da produção, quando se adentra no local oculto da produção, espaço esse em que se dá a produção da mais-valia.

Citando uma vez mais Décio Saes, o Estado burguês procura negar um coletivo, as classes sociais, para afirmar outro coletivo, o Povo-Nação. No Estado-Nação está colocada a igualdade jurídica, igualdade esta baseada no individualismo e no isolamento do trabalhador dentro e fora da fábrica. Numa operação ideológica, o Estado burguês procura representar a unidade dos membros das classes sociais antagônicas no coletivo Povo-Nação, além disso, o Estado burguês procura "neutralizar a tendência à formação de comitês de fábrica, sindicatos operários, partidos revolucionários; isto é, atomizar os produtores diretos, conservando-os num estado de massa, e impedindo a sua constituição em classe social."23

Estes aspectos se tornam ainda mais prementes a partir da década de 1970, no contexto de reconfiguração da relação sócio-metabólica capitalista. Lipovetsky, mencionado acima, já fazia referência a esse novo cenário. Dentre as consequências da difusão do neo-liberalismo e da chamada globalização está o engendramento de uma nova morfologia do trabalho.

Ricardo Antunes ${ }^{24}$ relaciona a implantação das novas condições de trabalho com a difusão do toyotismo, uma forma das empresas capitalistas garantirem a acumulação de maneira mais flexível e ajustada às novas realidades da reprodução capitalista. Têm-se assim a estruturação de empresas flexíveis e o pano de fundo de tais modificações estruturais remete às vitórias políticas do neo-liberalismo. Portanto,

... essa restruturação produtiva fundamentou-se no que o ideário dominante denominou como learn production, isto é, a enxuta "empresa moderna", a empresa que restringe e limita o trabalho vivo, ampliando o maquinário tecnocietifico, que Marx denominou como trabalho morto. E que redesenhou a planta produtiva de modo bastante distinto do taylorismo/fordismo, reduzindo enormemente a força de trabalho vivo e ampliando intensamente sua produtividade, reterritorializando e mesmo desterritorializando o mundo produtivo, pois noções de espaço e tempo transformam-se profundamente..$^{25}$

23 Idem. op. cit., p. 31.

24 ANTUNES, Ricardo. Desenhando a nova morfologia d o trabalho: As múltiplas formas de degradação do trabalho. Revista Crítica de Ciências Sociais [online], 83, 2008.

25 Idem. op. cit., p. 21. 
As consequências disso não tardaram a ser percebidas, com o desemprego em larga escala, a precarização estrutural do trabalho e a perda de direitos políticos duramente conquistados pela classe trabalhadora ao longo da história das lutas de classes.

A derrocada das experiências ligadas ao chamado socialismo real e essas mudanças estruturais no mundo do trabalho têm levado muitos teóricos a defender o fim do trabalho. Alguns autores como Robert $\mathrm{Kurz}^{26}$, ao empreender uma radical crítica do valor e do capital como pseudo-sujeito automático, procura negar mesmo os fundamentos da tradição do esclarecimento (Iluminismo) e do movimento dos trabalhadores. Kurz, apesar da grande significação de suas reflexões, ao criticar o que ele denomina de "marxismo atinente ao movimento dos trabalhadores", corre o risco de deixar o marxismo manco. Afinal, quais os sujeitos vão lutar contra a intensificação da lógica do valor e da estruturação e intensificação da distopia capitalista vigente?

Como afirma Antunes, temos que olhar para a nova morfologia do trabalho, que envolve ainda o operariado industrial e rural clássicos, embora em encolhimento (contudo levando-se em contra as especificidades dos casos das regiões Norte e Sul do planeta), até a formação de todo um contingente de assalariados de serviços, trabalhadores terceirizados, subcontratados, temporários. Por exemplo, trabalhadores de telemarketing, call centers, motoboys, assalariados de fast food e de hipermercados. ${ }^{27}$

Tanto teórica como politicamente, é preciso combater as contradições da sociedade capitalista e o caráter, em grande medida, formal da sua emancipação política. Ou seja, a fundação da comunidade política na verdade instaura a "proclamação do direito do homem egoísta, dissociado de seu semelhante e da comunidade.” ${ }^{28}$. A burguesia historicamente acaba com a sociedade estamental, mas instaura a sociedade de classes, na qual, a partir de sua situação particular, se coloca como a única classe efetivamente emancipada.

Por isso, Marx procura contrapor a emancipação política burguesa da emancipação prática. Esta emancipação significaria não apenas a superação do trabalho estranhado, da alienação a que é submetido o trabalhador no processo produtivo, mas também a superação da sociedade do valor e do fetichismo do capital que historicamente, no contexto da difusão do capitalismo, adentrou a praticamente todos os poros da sociedade contemporânea. Contra essas

26 KURZ, Robert. Razão sangrenta: Ensaios sobre a crítica emancipatória da modernidade capitalista e de seus valores ocidentais. São Paulo: Hedra, 2010.

27 ANTUNES, Ricardo. Desenhando a nova morfologia d o trabalho: As múltiplas formas de degradação do trabalho. Revista Crítica de Ciências Sociais [online], 83, 2008, p. 31.

28 Marx, apud: WEFFORT, Francisco C. Marx: política e revolução. In: WEFFORT, Francisco C. (Org.) Os clássicos da política 2. $5^{\text {a }}$ ed. São Paulo: Editora Ática, 1995, p. 255. 
forças insuportáveis, o proletariado aparece como classe universal, pois ao se emancipar, liberta a si e a toda a sociedade, na medida em que deve abolir todas as classes. ${ }^{29}$ Dessa forma, a emancipação efetiva da classe trabalhadora deve ter como pressuposto igualmente a superação de toda a forma de discriminação de gênero e étnica.

Enfim, procuramos salientar o aspecto absolutamente articulado que se apresenta na teoria da histórica marxista tanto os pressupostos epistemológicos quanto os seus pressupostos políticos. Walter Benjamin ao esboçar as suas teses Sobre o Conceito de História, escreve um dos textos fundamentais tanto da teoria da história quanto do marxismo no século XX. Nessas teses, a articulação dos aspectos políticos e científicos que devem orientar o historiador marxista é exposta com uma contundência poética e alegórica. Escreve-nos Benjamin:

A verdadeira imagem do passado perpassa veloz. O passado só se deixa fixar, como imagem que relampeja irreversivelmente, no momento em que é reconhecido. "A verdade nunca escapará" - essa frase de Gottfried Keller caracteriza o ponto exato em que o historicismo se separa do materialismo histórico. Pois irrecuperável é cada imagem do passado que se dirige ao presente, sem que esse presente se sinta visado por ela. ${ }^{30}$

Nas teses, Benjamin estabelece uma intensa polêmica com o historicismo (Escola Metódica), ressaltando que sua cientificidade é baseada em pressupostos burgueses, realizando, assim, uma história da perspectiva dos poderosos que sempre venceram. O historiador marxista, do contrário, deve fixar uma imagem do passado que relampeja irreversivelmente, e que se perderá se alguém no presente não procurar recuperá-la. Essa imagem é proveniente da história dos oprimidos ao longo dos tempos. O historiador deve estar atento ao chamado dos que são vítimas da tirania e da humilhação perpetrada pelos poderosos no decurso da história. Mas para que isso ocorra é preciso que o historiador esteja munido de pressupostos teóricos adequados para fazer jus a esses apelos vindos do passado. Benjamin define quem deve ser o sujeito histórico a ser privilegiado pelo materialismo histórico:

O sujeito do conhecimento histórico é a própria classe combatente e oprimida. Em Marx, ela aparece como a última classe escravizada, como classe vingadora que consuma a tarefa da libertação em nome das gerações de derrotados. Essa consciência, reativada durante algum tempo no movimento espartaquista, foi sempre inaceitável para a social-democracia. Em três decênios, ela quase conseguiu extinguir o nome de Blanqui, cujo eco abalara o século passado. Com isso, ela a privou de suas melhores forças. A classe operária desaprendeu nessa escola tanto o ódio como o espírito de sacrifício. Porque um e outro se alimentam da imagem dos antepassados escravizados e não dos descendentes liberados. ${ }^{31}$

\footnotetext{
29 Idem. op. cit., p. 256.

30 BENJAMIN, Walter. Teses sobre o conceito da história. In: Obras Escolhidas. Vol. 1. Magia e técnica, arte e política. São Paulo: Brasiliense, 1994, p. 224.

31 Idem, op. cit., p. 228-229.
}

CANOA DO TEMPO - Revista do Prog. de Pós-Gradução em História. Manaus, v.10 - no1, ag. 2018. 
Em contraposição a reprodução da perspectiva do progresso burguês que, contraditoriamente, a social-democracia alemã do entre-guerras alimentava, Benjamin, em sua crítica contundente a essa noção de progresso, mostra que a esquerda tem que alimentar as suas lutas e suas perspectivas do presente, a partir e em nome das gerações de derrotados do passado. Fazer da luta dessas gerações passadas um aprendizado e uma inspiração para as lutas no presente.

Como coloca Eric Hobsbawm ${ }^{32}$, é preciso pensar efetivamente o materialismo histórico como ponto de partida e não como ponto de chegada. Ou seja, empregar a teoria marxista da história como tendo um valor heurístico, como propostas de trabalho para a realização de pesquisas concretas. ${ }^{33}$ Só assim, se pode combater todo o perigo de dogmatização e enrijecimento do materialismo histórico.

Por outro lado, é preciso neste início de século XXI, enfatizar a atualidade e a relevância teórica do materialismo histórico, uma vez que,

... teremos que defender Marx e o marxismo dentro e fora da história, contra aqueles que os atacam no terreno político e ideológico. Ao fazer isso, também estaremos defendendo a história e a capacidade do homem de compreender como o mundo veio a ser o que é hoje, e como a humanidade pode avançar para um futuro melhor. ${ }^{34}$

Recebido em: 12/05/2018

Aceito em: 20/07/2018

\section{REFERÊNCIAS BIBLIOGRÁFICAS}

ADORNO, Theodor; HORKHEIMER, Max. Dialética do esclarecimento: fragmentos filosóficos. Rio de Janeiro: Zahar, 1985.

AGUIRRE ROJAS, Carlos Antonio. A historiografia no século XX: História e historiadores entre 1848 e...2025? São Paulo: Edusp, 2017.

ANTUNES, Ricardo. Desenhando a nova morfologia d o trabalho: As múltiplas formas de degradação do trabalho. Revista Crítica de Ciências Sociais [online], 83, 2008.

BARROS, José D’ Assunção. Teoria da história 3: Os paradigmas revolucionários. Petrópolis, RJ: Vozes, 2011.

32 HOBSBAWM, Eric. Marx e a história. In: Sobre história. São Paulo: Cia das Letras, 1998, p. 183. 33 SARTRE, Jean-Paul. Questão de método. $3^{\mathrm{a}}$ ed. São Paulo: Difusão Europeia do Livro, 1972, p.26-27. 34 HOBSBAWM, Eric. Marx e a história. In: Sobre história. São Paulo: Cia das Letras, 1998, p. 184. 
BENJAMIN, Walter. Teses sobre o conceito da história. In: Obras Escolhidas: Magia e técnica, arte e política. Vol. 1. São Paulo: Brasiliense, 1994.

EAGLETON, Terry. As ilusões do pós-modernismo. Rio de Janeiro: Zahar, 1998.

FERNANDES, Florestan. (org.). K. Marx, F. Engels. História. Col. Grandes Cientistas Sociais, 36. São Paulo: Ática, 1983.

HOBSBAWM, Eric. Marx e a história. In: Sobre história. São Paulo: Cia das Letras, 1998.

KOSELLECK, Reinhardt. Ponto de vista, perspectiva e temporalidade - contribuição à apreensão historiográfica da história. In: Futuro passado - contribuição à semântica dos tempos históricos. Rio de Janeiro: Contraponto : Ed. PUC-RJ, 2006.

KOSIK, Karel. Dialética do concreto. Rio de Janeiro: Paz e Terra, 1969.

KURZ, Robert. Razão sangrenta: Ensaios sobre a crítica emancipatória da modernidade capitalista e de seus valores ocidentais. São Paulo: Hedra, 2010.

LIPOVETSKY, Gilles. Tempo contra tempo ou a sociedade hiper moderna. In: Os tempos hipermodernos. São Paulo: Bartcarolla, 2004.

MARX, Karl. Manuscritos econômicos - filosóficos. São Paulo: Boitempo, 2004.

SAES, Décio. O conceito de Estado Burguês. In: Estado e democracia: Ensaios teóricos. Campinas, SP: IFCH, 1994.

SARTRE, Jean-Paul. Questão de método. $3^{\mathrm{a}}$ ed. São Paulo: Difusão Europeia do Livro, 1972.

WEFFORT, Francisco C. Marx: política e revolução. In: WEFFORT, Francisco C. (Org.) Os clássicos da política 2. $5^{\text {a }}$ ed. São Paulo: Editora Ática, 1995. 